\title{
ANÁlisis CRÍtico de los deREchos HuMANOS DESDE LA MODERNIDAD ALTERNATIVA RADICAL
}

\author{
MARIO MAgaLLÓN ANAYA ${ }^{1}$
}

REsumen: Actualmente los sujetos individuales, sociales, colectivos y comunitarios tienen grandes problemas para elegir cuál y qué es lo más adecuado para la construcción de una ética, una política, un sistema jurídico, un sistema económico, etc., esto, en gran medida, es resultado de un mundo global capitalista, en el que las élites capitalistas económicas globales de las metrópolis dominantes europeas y norteamericanas determinan el rumbo de nuestras sociedades. En este contexto, los derechos humanos deben convertirse en un arma de reivindicación de la clase humana explotada y reprimida por los dominadores. Lo que se trata de hacer hoy es enriquecer y resemantizar la idea de dignidad humana con justicia y equidad solidaria en libertad y democracia; desarrollar una forma alterna de tratar los derechos humanos desde un análisis filosófico práctico, es decir, desde una propuesta ontoepistémica y fenomenológica que, con ayuda de la herramienta hermenéutica analógica, pretenda construir una fundamentación ontológica que abarque tanto a la universidad del ser humano como su contextualidad existencial. El género humanos, interpretado como la humanidad, debe colocarse en el centro de todas las políticas y los derechos, sólo así podemos replantear los derechos humanos como derechos morales, éticos y políticos.

Palabras clave: Derechos humanos, hermenéutica analógica, dialéctica intercultural, modernidad alternativa radical, fenomenología ontoespitémica, fundamentación, dignidad humana, justicia, libertad, solidaridad.

Aвstract: Gurrently, individual, social, collective and communitarian face great problems in determining an appropriate foundation for building an ethical, political, legal, and economic

1 Investigador Titular del Centro de Investigaciones sobre América Latina y el Caribe de la UNAM (CIALG) y profesor de la Facultad de Filosofía y Letras de la misma universidad; sus líneas de investigación son la filosofía de la educación en América Latina y la filosofía política en América Latina. Contacto: <mariom@ servidor.unam.mx>. 
system. This, in a broad sense, is the result of a global capitalist system in which economic elites, found in sprawling European and American cities, determine the direction of our societies. In this context, human rights must become a tool for vindication by the repressed and exploited social classes. What is sought after today, is to enrich and supplement the idea of human dignity, with the notions of justice, equality, and democracy. Developing an alternate way to see human rights from a practical philosophic view, it means from an onto-epistemic and phenomenological proposal aided by analogical hermeneutics' tools that try to make an ontologic basis, which covers the human universality as well its existential contextuality. The human genre, interpreted as humanity must place itself at the center of all policies and rights, only this way it is possible to rethink human rights as moral, ethical and political rights.

KEY WORDS: Human rights, analogical hermeneutics, intercultural dialectic, radical alternative modernity, ontoepistemic phenomenology, basis, human dignity, justice, freedom, solidarity.

SumARIO: I. Dignidad humana y derechos en un mundo global; II. Modernidad: dignidad humana ética y derechos.

\section{Dignidad humana y DeRechos EN UN MUNDo global}

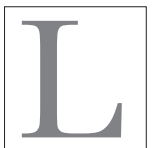

a filosofía hermenéutica analógica dialéctica e intercultural de los derechos humanos ${ }^{2}$ mirada desde la modernidad alternativa radical es una reflexión filosófica crítica sobre los fundamentos ontofenoménicos de los derechos humanos, del ser

2 ¿Por qué la utilización de la hermenéutica analógica dialéctica e icónica, en investigaciones de este carácter, especialmente, en el estudio de los derechos humanos? Porque la hermenéutica analógica dialéctica e icónica supone una idea del ser humano libre, pensante, consciente, responsable, intérprete, crítico, pero además, prudente. Es la reflexión de un ente que puede deliberar libremente, dialogar y poner en común problemáticas filosóficas, políticas, antropológicas e históricas, etc., para discrepar para comprender y hacerse comprender en el análisis dialéctico y dialógico de los problemas que afectan a la existencia humana y a sus condiciones de vida y de existencia. Mauricio Beuchot considera que: "Eso es lo que implica la hermenéutica: una idea del hombre reflexivo libre, que aporta argumentos para sustentar lo que dice y hace, lo que interpreta. 
humano y de la ética desde un sujeto históricamente situado en una realidad histórica, concreta, material; que busca analizar las posibilidades del diálogo intercultural y de comunicación horizontal en un escenario de sociedades asimétricas, en el mundo globalizado neoliberal capitalista, en una relación intercontextual de imperativos categóricos: sistémicos y asistémicos, simétricos y asimétricos dentro de un horizonte histórico, antropológico, intercultural, colectivo y comunitario como construcción de sentido y significación en el proceso de la globalización neoconservadora liberal, económica, política y social construida sobre la base de una analogía paradojal entre los derechos humanos de la tercera generación, de la solidaridad y de la ética social y la colectiva, con la cuarta generación de la ciudadanía, de la conservación del medio ambiente, de la ética ecológica, del sujeto social, etcétera. ${ }^{3}$

Para tal objeto utilizaremos como inferencia analítica la herramienta de método de la hermenéutica analógica dialéctica e icónica, porque

En efecto, la hermenéutica analógica tiene, gracias a la noción de analogía, un aspecto dialéctico. La analogía tiene una dialéctica detrás de ella, o que la acompaña. No es una dialéctica como la hegeliana, que llega a una síntesis, asunción y superación de los opuestos, sino una dialéctica que no concluye, que no lleva a los opuestos a una síntesis perfectamente conciliadora. Tiene una conciliación frágil y hasta trágica. No es como la dialéctica de Hegel, sino como la de Heráclito, Empédocles, Cusa, Bruno, Kierkegaard, Nietzsche

Además una hermenéutica analógica supone un ser humano prudente, que la analogía es proporción, y la prudencia es o phronesis no es otra cosa más que la proporción hecha carne propia, la analogía hecha vida nuestra". Esta es la expresión de un ejercicio del pensar hermenéutico, dialéctico y dialógico. Mauricio Beuchot Puente y José Barrientos Rastrojo, La filosofía aplicada según la hermenéutica analógica, México, Editorial Torres Asociados, 2013, p. 78.

3 Cfr., Ana Luisa Guerrero Guerrero, "Derechos humanos y ciudadanía en América Latina", Latinoamérica. Revista de Estudios Latinoamericanos, CIALC/UNAM, 2010, pp. 109-139. 
y Freud. Es decir, Heráclito plantea la coexistencia de los opuestos, como el fuego y el leño, el arco y la lira; y no la reconciliación. Los opuestos viven de su propio conflicto en tensión; conservan sus propiedades antitéticas y de su propia lucha va surgiendo su mutua colaboración. Acaban por trabajar el uno para el otro. ${ }^{4}$

Es necesario advertir que la hermenéutica beuchotiana es un instrumento metódico analógico dialéctico y dialógico abierto que busca el punto medio, no la positivización cientificista, pero, tampoco la relativización subjetivista, equivocista y personal del saber, sino de la realidad dialéctica y crítica en un horizonte de sentido y de significación. Este es un esfuerzo de la filosofía hermenéutica analógica e icónica porque a través de ella se busca alcanzar la objetividad de la verdad dialécticamente analizada, a través del punto medio, del equilibrio y de la frónesis; por ello, no se busca la absoluta razón, sino la construcción dialéctico-procesual que incide en la filosofía, la historia, la literatura, la política, la economía, la antropología, la cultura; en la ciencia y la técnica y la tecnología; en los derechos humanos, la ética, etcétera.

La hermenéutica analógica dialéctica e icónica beuchotiana-mexicana, no sólo es un método consistente y riguroso para atender los problemas que nos ocupan, sino un instrumento filosófico para reflexionar sobre el mundo de la vida, de la existencia y de la condición humana en el mundo, en su temporalidad, en la oquedad de la existencia, de la vida en un mundo en crisis permanente y hasta hoy sin superación. Es allí donde la prudencia "tiene que ver mucho con la noción de aplicación y, siempre es buscar la relación de algo particular, como es el texto, con algo universal, como es la tradición", ${ }^{5}$ que como factor epistemológico y ontológico, tiene

4 Mauricio Beuchot Puente y José Barrientos Rastrojo, La filosofía aplicada según la hermenéutica analógica, México, Editorial Torres Asociados, 2013, p. 74.

5 Mauricio Beuchot, Phrónesis, Analogía y hermenéutica, México, Seminarios: Facultad de Filosofía y Letras/UNAM, 2007, p. 85. 
que ver con la contingencia, es decir lo que no es todavía, pero que puede ser de otra manera. Porque,

Nunca quizá como ahora se intensifica la vivencia de historicidad y temporalidad: de fin y comienzo de algo nuevo, de algo que parece traer consigo una singular "otredad" y, con ello, la experiencia del devenir acentuada en su constitutivo-no-ser: de lo que ya no es, y lo que no es todavía. Se acrecienta, así, la angustia ante la indeterminación e incertidumbre del futuro, ante su vacío y cuanto lleva de imaginable e imprevisible. Pero al mismo tiempo, crece también el temor ante aquello del porvenir que se va esbozando en múltiples rasgos de amenaza y peligro; de algo que quebranta cimientos profundos, estructuras fundamentales de nuestro mundo conocido, el que históricamente hemos habitado. Las dos cosas son ciertas: lo imprevisible y, a la vez, lo previsible de aquello que se avecina. Estamos ante el momento crucial en que se abre un hiato temporal entre dos eras, en que se percibe tanto la oquedad del cambio como las desafiantes prefiguraciones del porvenir. ${ }^{6}$

Este mundo de retos y de posibilidades, como se percibe, no parece ser nada simple, porque es de una complejidad inusitada que requiere de un instrumental hermenéutico analógico interpretativo y explicativo que puntualice y potencialice las posibilidades dialécticas de interpretar y explicar críticamente lo que se vive en una multiplicidad de tiempos y espacios, donde los sujetos individuales, sociales, colectivos y comunitarios tienen grandes problemas para elegir cuál y qué es lo adecuado y correcto ética, política, social, cultural y económicamente en el mundo global capitalista; donde los gustos y las decisiones ya han sido decididas por las élites económicas globales de las metrópolis dominantes europeas y norteamericanas, donde quedaría incluidas,las de Oriente, especialmente,

6 Juliana González, "Sobre el porvenir del homo humanus", en León García Soler (coord.), La palabra y los Derechos Humanos, Comisión Nacional de los Derechos Humanos, México, 2004, p. 203. 
China, ${ }^{7}$ en este mundo de saberes consensuados a través de formas subliminales difundidas en de los medios: TV, radio, cine, periódicos y revistas como algunas de las redes sociales, las que no dejan de estar vinculadas e influidas ideológicamente por los intereses del capital, del Estado-nacional y del Estado Global, de las empresas globales y de los grupos de interés económico mundial, no obstante la amplia libertad y "democracia" con que operan.

Es obvio que el mundo actual presenta un futuro amenazante, porque ha cambiado el sentido común del sujeto y de la sociedad, o, porque ¿ya no hay sentido común? porque ya no existe el tiempo suficiente para meditar y reflexionar críticamente nuestras ideas, decisiones y acciones; en una realidad mundial donde los medios de vida dominantes en las sociedades, comunidades, colectivos, grupos e individuos son de muy diverso carácter, pero sin fines éticos, es decir, sin una teleología éticamente humanista correctamente orientada, donde el centro sea el ser humano: la humanidad toda. En la coyuntura parece dominar una visión inmediatista que impide mirar con claridad hacia donde se quiere ir.

7 El destacado y reconocido diplomático y economista, el maestro Arturo González me ha permitido hacer esta afirmación, cuando al respecto de China señala que: "Pensar en las perspectivas de la relación entre México y China no puede desvincularse de las realidades geopolíticas de esta segunda década del presente siglo que se distingue por dramáticos cambios en el escenario económico, político y militar mundial que apunta a reacomodos en el poder mundial. Estamos viendo pasar ante nuestros ojos el estancamiento europeo y la lenta recuperación de los Estados Unidos posteriores a la crisis financiera, al tiempo que testimoniamos la permanencia de China como la segunda fuerza económica global a pesar de que ha ajustado su explosiva expansión de las décadas recientes, a tasas menos espectaculares. [...] La preponderancia económica china, tanto como productor de todo tipo de bienes, como gran consumidor de materias primas, es una situación que trae aparejada ipso facto una serie de responsabilidades internacionales propias de las potencias ya que directa e indirectamente afectan al comercio internacional, los movimientos de capital, la estabilidad monetaria y obviamente las relaciones de poder". Relaciones México China: "Intermedio luego de dimensionar el tamaño de China en el mundo". México, Cd. Universitaria, 19 de junio de 2014, p. 1. [N. E. Las cursivas son del autor]. 
En la actualidad se está construyendo un futuro, desde un presente con grandes inconsistencias teóricas, lógicas y epistemológicas, sin fundamentos históricos, políticos, sociales y culturales orientadores. La promesa de la modernidad occidental y el desarrollo de la razón tecnológica instrumental, del "conocer para dominar" y "dominar para conocer" a la naturaleza y al ser humano, de raíz baconiana, se ha cumplido con creces, empero, esta invención humana se ha vuelto contra su creador y el daño se vuelve a veces, aunque no siempre proporcional al logro y a la supuesta emancipación humana de la ciencia, la técnica y la tecnología, lo cual se ha tornado en una nueva modalidad de esclavitud y vasallaje, de sumisión trágica y fatal al mundo del "progreso" de la modernidad occidental europea, para convertirse en una amenaza, lo que impide prever la mayor destrucción que el progreso de la modernidad ha ejercido sobre sí mismo y sus obras.

El esfuerzo y el fallido intento de la transformación de la condición humana ha llevado, al mismo tiempo, a su sometimiento a través de los procesos de la industrialización, de la aplicación de la ciencia y la tecnología, los que han convertido en rehenes a los seres humanos, predestinándolos a la destrucción y a la muerte. La gran amenaza es el colapso y destrucción del planeta, ante los resultados de daños irreversibles a la ecología, a la biósfera, al medio ambiente y a la vida originados por los éxitos científicos y tecnológicos.

Sin embargo, ante el riesgo de la destrucción total se oponen poderosos impulsos nuevos en favor de la sobrevivencia, aunque las estrategias y alternativas no son claras y algunas apenas son pergeñadas. Ante esto, dónde quedan los derechos humanos; previamente a ellos, lo más importante es la defensa de la sobrevivencia del ser humano. Es una extraordinaria propuesta de posibilidad y de oportunidad para la creación de una necesaria producción de bienes para la sobrevivencia y ampliar las posibilidades de cura no sólo espiritual sino también material; es decir, en los diversos órdenes políticos, sociales, económicos, como, a la vez, la cura del ser huma- 
no en su ethos propio, en una proyectiva propuesta, donde el género humano se coloque como centro y las innovaciones tecnológicas y las tecnociencias se orienten hacia la salvación de la humanidad.

Empero, todo parece indicar que estamos ante una encrucijada histórica, donde el dilema permite anunciar:

Una nueva Aurora de la libertad humana o por el contrario su ocaso o muerte. [...] Se trata de cambios que conllevan a una verdadera mutación biológica y ontológica de la condición humana. [...] Múltiples son los signos, por desgracia, de que estos nuevos ofrecimientos tecnológicos ponen en riesgo extremo la existencia de lo humano del hombre, en irónico trueque de su libertad por la supuesta "felicidad" de un ente sin ambigüedades, perplejidades, conflictividades, sin la necesidad intrínseca del otro. ${ }^{8}$

Ante esta realidad mundial de incertidumbre e indeterminación, donde no existen principios consistentes orientadores de las formas del ser y del pensar, es urgente hacer un alto en el camino para buscar estrategias que orienten los principios éticos, políticos y culturales y de los derechos humanos de la cuarta generación.

Estamos ante la necesidad de un nuevo saber de la condición humana y la condición ética, como también de los problemas de la libertad, de la temporalidad, la razón moral, los criterios de valor. Pero también es menester preguntarse de qué sirve el saber filosófico y el saber ético ante este proceso tan indefectible como acelerado del progreso científico y tecnológico, ante la "fuerza mayor" de la razón cibernética, ante la supuesta "perfección" del mundo virtual. [...] El peligro más grave está en que éste sea inadvertido, voluntaria e involuntariamente: se haya incluso en la tendencia, motivada por intereses de poderío y lucro, a minimizar o soslayar los riesgos. Los mayores peligros son, [...] la inconciencia de la capacidad crítica de ésta y de su alcance desmitificador. La acción filosófica mantiene viva, en efecto, la vocación de asombro y problema, que impide dar nada por consabido y, menos aún, inevitable. ${ }^{9}$

8 Juliana González, op. cit., pp. 209-210.

9 Ibid, p. 212. 
Para dialogar de o sobre las generaciones de los derechos humanos y con todos aquellos que se preocupen por la sobrevivencia del ser humano, de la humanidad, se requiere asumir una posición reguladora ético-política-social y de derecho que refuerce la legalidad, la legitimidad lógica y formal, de justicia, de equidad, de derecho y de juridicidad en la practicidad dialéctica e histórica concreta, que se expresa y muestra, tanto explícita como implícitamente, en la arquitectura expositiva argumental y dialógica. Es decir, no se trata sólo de probar filosóficamente los derechos humanos y la eticidad, sino, más bien, de crear un consenso fáctico y formal, en la construcción conceptual, allí donde los principios éticos-políticos y de derecho valen por sí mismos, pero que requieren ser convalidados en la práctica de la vida humana.

Ello requiere replantear los derechos humanos como derechos morales, éticos y políticos. Los derechos humanos conllevan implícitas exigencias éticas y de derecho en una comunidad política que requiere y demanda el reconocimiento, protección y garantía del Estado, de la sociedad, del poder político y del derecho igualitario comunitarista, que va más allá de la inmediatez, para convertirlos en propiedad común a todos los seres humanos, en una exclusiva del ser humano, fundada en la construcción formal y en la dialéctica filosófica entre el iusnaturalismo y iuspositivismo.

La realidad de hoy, en crisis, requiere de la apertura de nuevas fronteras en un capitalismo que demanda imaginación y creatividad para construir nuevos espacios y tiempos formales en una realidad fragmentada, que es consecuencia del rompimiento y superación de las fronteras territoriales nacionales, regionales y mundiales, por las élites económicas globales. Las formas económicas, políticas y culturales trascienden las concepciones del tiempo lineal y propician el rompimiento del pacto social creando nuevas estrategias de dominación mundial, neoliberal, posmoderna y poscolonial, en los centros del poder económico, ante una realidad donde las fronteras territoriales y transfronterizas ya casi no existen y donde dominan 
fronteras virtuales, que muy poco tienen que ver con la experiencia de la población mundial y con la vida toda.

Las características del mundo de negocios y las formas especulativas de producción y de consumo muestran la falta de compromiso de las élites globales con la población mundial, este desapego es la causa de la pérdida de estas identidades fijas, porque ya no tienen un punto fijo geográficamente, sino más bien, ahora son flotantes, transfronterizas; algo similar, respecto de la identidad acontece con los individuos, las comunidades humanas, las naciones y las regiones, etc., que han sido violentadas por las metrópolis económicas del poder mundial, con el rompimiento de los lazos de las tradiciones locales, nacionales y regionales, orientadoras de nuevos horizontes ideológicos, políticos, sociales y culturales.

En consecuencia, la fundamentación filosófica de los derechos humanos tradicional es insuficiente para explicar la nueva dimensión de éstos. Se trata de enriquecer y resemantizar la idea de dignidad humana con justicia y equidad solidaria en libertad y democracia, eje regulador de las relaciones humanas, de los derechos, de las libertades, etc. Lo cual implica mostrar, descubrir y hacer presente los derechos humanos y, a la vez, poner en tela de juicio los derechos comúnmente aceptados, como el problema de la jerarquización entre ellos y con respecto de las otras cosas eminentemente humanas.

Porque, allí

Donde no habita la justicia, ni siquiera como ideal o como búsqueda, la dignidad de la persona es mera palabrería. A fin de cuentas, la justicia intenta hacer realidad esa hipotética igualdad de todos los humanos y la no menos dudosa libertad en tanto derechos fundamentales de lo individual. Derechos que son el requisito de una calidad de vida que debe ser objeto luego de la conquista individual. ${ }^{10}$

10 Victoria Camps, Virtudes públicas, Madrid, Espasa Calpe, 1990, pp. 33-34. 
Porque la justicia, la libertad, la solidaridad, la autonomía, la tolerancia, la comunidad, etcétera, ya no son sólo, o no se deben reducir a la "fundamentación teórica abstracta", sino a la construcción dialéctica y dialógica de aquellos aspectos que no se deciden en abstracto, sino en la concreción específica, material e histórica. Efectivamente, porque "es muy difícil señalar qué derecho humano es el primero y cuáles tienen prioridad sobre los otros. Por encima de todo se niega que la postulación de esos derechos, se puedan hacer como una cuestión de legitimidad ética, independientemente de ciertas bases económicas y políticas". ${ }^{11}$

La idea de la justicia, desde el valor de la eticidad individual y colectiva, en este sentido de la practicidad, es esclarecer las razones y los motivos para mejorar la práctica de la justicia de forma universal incluyente del género humano, donde se encuentra implícita la superación de la injusticia, lo cual se aleja de la supuesta e hipotética justicia perfecta, porque ello supone claras diferencias con las teorías de la justicia en general de la actualidad. Una idea de la justicia mejor ubicada está constituida por las filosofías prácticas: la ética, la antropología filosófica, la filosofía de la educación, la filosofía política en el mundo, no sólo occidental, sino también mundial.

Amartya Sen considera que

Si vivimos en un mundo local de creencias fijas y prácticas específicas el parroquialismo puede pasar desapercibido. [...] Considerar las opiniones de otros y sus razones puede ser una manera efectiva de determinar lo que la objetividad (lógico-racional) exige. Para concluir esta discusión, la evaluación de la justicia exige compromiso con "los ojos de la humanidad"; primero, porque podemos identificarnos con los otros y no sólo con nuestra comunidad local; segundo, porque nuestras opciones y acciones pueden afectar las vidas de otros aquí y allá; y tercero, porque los que los otros ven

11 Mauricio Beuchot, Filosofía y derechos humanos, México, Siglo XX, 1993, p. 25. 
desde sus respectivas perspectivas históricas y geográficas pueden ayudarnos a superar nuestro propio parroquialismo. ${ }^{12}$

En este sentido puede decirse que reflexionar en torno a los derechos humanos y la justicia apunta hacia una tensión entre lo particular y lo universal, lo individual y lo colectivo, lo inmediato y lo trascendente, lo local y lo nacional, la hegemonía y la contrahegemonía, etcétera, lo cual lleva al problema de la globalización y de la hegemonía. Todo esto complica la interpretación de los derechos humanos que impide o hace muy difícil la síntesis cultural de ellos en la unidad de la diversidad y de la diferencia.

Mi tesis es que mientras que los derechos humanos sean concebidos como derechos humanos universales tenderán a funcionar como localismos globalizados en una forma de globalización desde arriba. Para poder funcionar como una forma de globalización cosmopolita contrahegemónica, los derechos humanos deben ser reconceptualizados como multiculturales. Concebidos como han estado, como universales, los derechos humanos siempre serán un instrumento de lo que Samuel Huntington llama el "choque de las civilizaciones", es decir, de la lucha de Occidente contra el resto del mundo, del cosmopolitismo del Occidente imperial contra cualquier concepción alternativa de la dignidad humana que esté socialmente aceptada en otra parte. ${ }^{13}$

En este sentido el problema de los derechos humanos es el lugar de la elucidación desde donde se expresan los intereses, desde un espacio de enunciación radical sin marginalización, ni exclusiones de nadie ni de nada que afecte la existencia, la vida misma, allí donde la inclusión de la totalidad del género humano se convierta en una realidad, ello deberá ser el hipotético teórico epistémico orientador de este pensar. Nos encontramos en una realidad en la cual es necesario reconocer y asumir la ductilidad del capita-

12 Amartya Sen, La idea de la justicia, México, Taurus, 2010, p. 159.

13 Boaventura de Sousa Santos, Descolonizar el saber, reinventar el poder, Uruguay, Trílce, 2010, p. 67. 
lismo, que le ha permitido mantener el control y la hegemonía en el mundo. El sistema capitalista lejos de agotarse ha alcanzado un nuevo esplendor. Tras la caída del bloque socialista y la crisis de las naciones en desarrollo, el capitalismo se presenta como la única opción para el ser humano; es allí donde los derechos humanos son profundamente violentados, no obstante la exigencia y respeto por las organizaciones internacionales, en el fondo lo que está detrás es el mercado total, tan acariciado por el neoliberalismo, desde las metrópolis imperiales y las empresas globales, basado en el hipotético falso de que los grandes problemas de la humanidad serán resueltos por el mercado total, para imponer una visión mercantil del mundo, donde todo se compra y se vende en el sistema neoliberal.

Esta ideología del mercado total permite ahora desentenderse de todas las funciones concretas de la economía. Todo se disuelve en simples expresiones mercantiles fuera de las funciones mercantiles no queda nada real. En la visión del mercado total, toda humanidad se agota en el destino de la maximización de las ganancias. Especialmente este pensamiento neoliberal puede desentenderse de cualquier compromiso con la vida humana, con la vida humana concreta, que ya no es más que un subproducto de la totalización de las relaciones mercantiles. ${ }^{14}$

La realidad mundial agobia los conceptos y categorías filosófico-políticas se han desgastado, hasta el extremo de no saber con precisión conceptual cuál es el sentido y el valor de las teorías y de los campos epistemológicos, éticos, políticos, sociales, económicos, culturales y de derechos. "El Occidente destruyó continentes, culturas y pueblos enteros. Realizó sacrificios humanos gigantescos que en su visión eran sacrificios necesarios para destruir la despotía y para traer, mediante el mercado, la libertad". ${ }^{15}$

14 Franz J. Hinkelammert, Crítica a la razón utópica, San José de Costa Rica, DEI, 1984, p. 89.

15 Franz J. Hinkelammert, Sacrificios humanos y sociedad occidental, San José de Costa Rica, DEI, 1992, p. 38. 
Por ello es necesario, en general, insistir en qué vamos a entender por derechos humanos en la actualidad, para no caer en la despotía, en las formas de control de los déspotas imperiales y de los totalitarismos y avanzar en la construcción de una ética incluyente de la totalidad del género.

Los derechos humanos son las exigencias fundamentales, morales y jurídicas, que brotan de la naturaleza y dignidad de la persona humana. Los derechos humanos tienen por fin el reconocimiento y respeto de la dignidad, valores e igualdad fundamental de las personas humanas, y la realización del bien común. ${ }^{16}$

Es importante señalar que todo ejercicio del pensar requiere navegar con la pluralidad y la diferencia en las relaciones ontofenoménicas históricamente situadas; porque todo lo humano y la humanidad misma, como unidad ontológica y fenoménica, se orientan por las pluralidad, la diferencia y la diversidad en la unidad dialéctico procesual e histórica del ser humano, porque éste es el modo de ser de lo humano. La onticidad humana es el modo de ser de lo humano en la fenomenicidad de la existencia.

Considerar a lo humano sólo desde la concepción "universalista occidental", "cosmopolita europea" es asumir formas de pensar absolutistas, unidimensionales, racistas y excluyentes, donde la pluralidad, la diferencia y la diversidad son inconsistentes formal y prácticamente, porque para la concepción europea, lo humano sólo es posible en una sola dimensión. "Más allá del capitalismo global y la modernidad occidental se requiere de una genealogía que busque los orígenes explícitos e implícitos, es decir que atienda tanto a las inclusiones como a las exclusiones para construir una concepción 'otra' de los derechos humanos desde la plurivocidad y el diálogo. Intercultural". ${ }^{17}$

16 Héctor Rogel Hernández, Diccionario de ética, México, Porrúa, 2008, p. 35.

17 Blanca Angélica Mejía Acata, El derecho a la diferencia como derecho fundamental en América Latina, 2014, p. 44, Tesis, UNAM-FFyL. 
El mundo histórico de la actualidad coloca a la humanidad ante una realidad de extrema destrucción de los seres humanos, de la vida socioambiental, de las relaciones humanas: sociales, políticas, económicas y culturales, de la relación del "cara a cara" de comunicación horizontal y diálogo en un ejercicio de dialogicidad entre los entes sociales y políticos. Estamos ante una crisis de contradicciones y de oposiciones, que sus consecuencias, según colegimos, van ser más negativas que positivas para la humanidad. La crisis ha constituido una estructura poliédrica de desgarramiento y de fragmentación.

Se viven tiempos de crisis negativas y profundamente fragmentadas:

Tiempos fractales son los nuestros, y la cajonera de ideologías y disciplinas con que organizamos nuestros saberes y nuestros haceres durante los últimos doscientos cincuenta años comienza a resultar un estorbo. Urge liberar la historia del fatalismo y recuperarla para la libertad. Necesitamos un pensamiento transdisciplinario, holístico, capaz de lidiar con el caos, la incertidumbre y los sistemas complejos de desarrollo no lineal. Y posiblemente también nos hace falta una remitologización de la política, un nuevo utopismoaurático que sepa provocar intuiciones totalizadoras como las del pensamiento salvaje de los premodernos. ${ }^{18}$

En este horizonte de reflexión se encuentra que la ética y el derecho tienen una complicada relación, que mirados desde la realidad de la modernidad radical, se muestra el rompimiento de las nuevas relaciones neoliberales globales en oposición de una relación solidaria con la justicia, la equidad social, la comunidad en busca del bien común.

Este problema se intensifica ante la falta de salidas de los nuevos conflictos, confrontaciones, oposiciones y contradicciones planteados a las nuevas ciencias humanas, sociales y naturales, las que están

18 Armando Bartra, Tomarse la libertad. La dialéctica en cuestión, México, Ítaca, 2010 , p. 19 . 
imposibilitadas de dar una respuesta y solución inmediata ante la complejidad de los problemas y las contradicciones que inciden en la construcción conceptual hermenéutica analógica interpretativa y explicativa.

Me da la impresión de que la sociedad actual, en medio de sus "clases políticas", no puede hacer nada mejor que darse una pausa para reflexionar sobre cuestiones fundamentales: la vida, la existencia, la ecología, los derechos, las libertades, la justica, la ciencia, la tecnología, etc. Es necesario ganar tiempo para un debate que emane de una indagación sobre las formas de organización política, social, económica y cultural del mundo. Probablemente habría que aludir a las deficiencias del personal político mundial donde se oculta un descontento global que aún no ha tomado forma; se trata de nuevas reconfiguraciones de los Estados aurorales que demandan tomar conciencia de las insuficiencias antropológicas y exclusiones racistas de alcance mundial. Por ello, en el mundo existe un problema que tensiona la reconstrucción y reconfiguración de las identidades personales y globales.

Algunos han querido "resolver" el problema proponiendo que se acabe "con las tribus", que nos constituyamos como humanos a través de una única cultura universal. Pero la realidad de nuestra condición es tozuda a este respecto y muestra que tal tarea, aparte de que no podría realizarse más que con fuerte violencia, es en la práctica inviable, porque como sentenció Waltzer, podemos acabar con las tribus, con grupos culturales concretos, pero no con la condición de tribalidad, por lo que la multiplicidad -y el reto por encontrar una convivencia armónica para la misma- volverá a aparecer. Es decir, no se trata de acabar con la tribalidad, sino con el tribalismo destructor, mal de la violencia entre grupos culturales, sino a potenciar la creatividad y la riqueza que puede suponer la diversidad de los humanos. En cualquier caso queda manifiesto que lo es ocasión de riqueza de bien -construcción de identidades en la diferencia- es ocasión de tentación de mal - pretender construirlas dominando o aplastando a los otros-: no podemos 
abordar lo primero sin afrontar lúcidamente lo segundo, que estará inevitablemente presente. ${ }^{19}$

En este escenario complejo destacan, en oposición al supuesto relativismo y subjetivismo, los valores y los derechos humanos ético-filosóficos. Esto de ninguna manera puede estar referido sólo al conflicto conceptual de las ideas puras del entendimiento, de la vieja modernidad, sino que se requiere de la construcción de metáforas donde inciden campos interdisciplinarios, transdisciplinarios y disciplinarios, lo que plantea la necesidad de navegar con la pluralidad del entendimiento y del conocimiento a partir de un horizonte ontoepistémico problematizador. Por ello hablar del conflicto de las ideas, o del uso de los conceptos, es hacer un uso normal del lenguaje para abrir un espacio reflexivo sobre la razón y el entendimiento. ${ }^{20}$

El problema político fundamental, social, económico, cultural, ético y de derechos humanos está radicado en las relaciones del individuo con el Estado. La crisis de estas relaciones ha envuelto a la crisis de los valores, de la ética, en fin, de las filosofías prácticas. Es la crisis de la comunidad humana y de los valores de justicia, libertad, equidad y solidaridad. Allí donde la justicia es la organización más o menos regulada de las libertades, las cuales no se dan en abstracto, sino en la experiencia de la vida, donde individuo y Estado son potencialmente opuestos y conflictivos y, a la vez, potencialmente complementarios, porque: "el ser humano es comunidad: el mundo es parte del ser humano". ${ }^{21}$

Es necesario persistir en la reflexión omniabarcante de la ética en los diversos campos de las humanidades, las ciencias sociales y de

19 Xabier Etxeberria, "El mal en las dinámicas identitarias", en Marina González Martínez (coord.), El mal y sus discursos. Reflexiones para una visión ética del mundo, México, Tecnológico de Monterrey/Miguel Ángel Porrúa, 2007, pp. 48-49.

20 Cfr., Eduardo Nicol, La vocación humana, México, El Colegio de México, 1953, p. 90.

21 Ibid, loc. cit. 
los derechos. Cuando se piensa en ética, refiere al bien, la felicidad, la virtud, la justicia, al bien común, pero muy pocas veces se navega con sus opuestos: el mal, la infelicidad, el vicio, la injusticia...; normalmente se piensa a los primeros como nociones absolutas y universales.

Desde el horizonte filosófico de la modernidad alternativa y radical se busca una síntesis dialéctica abierta de lo negativo y de lo positivo, buscando el punto medio, de la temperancia, de la fronesis para buscar trascender las pretensiones esquemáticas unificadoras de la filosofía y de la éticas tradicionales y las fragmentadas, personales y subjetivas.

La filosofía moderna no puede concebir la violencia, el mal más como negatividad, es por ello que necesitamos otra idea de filosofía que no busque ser un sistema unificador, dicotómico. El racionalismo tiene una tendencia unificadora del mundo al que hay que marcar límites, porque para poder plantear una forma de pensamiento multidimensional tenemos que partir de problematizar el estatuto epistemológico de nuestro conocimiento en general y del conocimiento antropológico en particular. ${ }^{22}$

Por ello es necesario resemantizar una filosofía multidimensional y multidiversa, desde un núcleo y eje problematizador como fuerza ontoepistémica que la unifique en una figura conceptual de dialéctica abierta en la totalidad unificadora.

Sin embargo, hablar de derecho implica la posibilidad de ser garantizado social e históricamente en la totalidad del ser humano históricamente situado, porque un ser ilimitado e infinito carece de derechos, porque el derecho en sí es una limitación, lo mismo sucede con un ser limitado, porque tampoco los tiene, porque no es capaz de superar sus límites actuales, es incapaz de novedad, pues su desarrollo está predeterminado. "La acción es la forma propia del ser actual en el hombre".

22 Marina González Martínez, "La construcción del mal”, en Marina González (coord.), op. cit., pp. 19-20. 
Por esto, la excepcionalidad, en el orden de la individualidad humana, es una forma de representación histórica: el hombre singular expresa fielmente aquello de que precisamente se distingue. El mundo es una presencia dialógica permanente, que no logra disiparse ni desvanecerse en situaciones de mayor soledad o reclusión existencial. El carácter distintivo de la existencia histórica es la expresividad. La vida humana es expresión, es diálogo. La expresión significa comunión. ${ }^{23}$

Por ello, puede decirse que los derechos se refieren a los hechos. Porque los derechos son también hechos, son, en una palabra, creaciones humanas. Como tales, pertenecen, sin embargo, a una distinta zona ontológica de los hechos. Un derecho es una regla de la existencia, no sólo una posibilidad determinada; y cuando no está efectivamente establecido y mantenido, un derecho es en sí mismo solamente una posibilidad consciente y deseada, por otro nombre llamado ideal.

Por ello resulta necesario distinguir los niveles ontológicos para determinar el nivel adecuado de la existencia humana actual, como el fundamento de sus posibilidades garantizadas social y legalmente. De donde se puede derivar el valor de la libertad como hecho y como derecho. ${ }^{24}$

La historia es el hecho de la libertad. Esto nos llevaría a llamarla faciendi más bien que factum, porque la historia es un devenir. Su movimiento no sólo va del presente hacia el futuro, sino también muy persistentemente, del pasado hacia el presente. El pasado no es estático, aunque lo hecho sea irreparable, sino integrado en la dinámica general de la existencia. El tiempo rehace el pasado; lo rehace cada vez que emprendemos un nuevo camino, algo que nunca se hiciera antes; cada vez que actualizamos alguna potencia insospechada. Toda actualidad vital contiene una potencia, y este [sic] sería el nombre apropiado del presente ontológico. Cada presente emerge de un pasado, no sólo en la continua secuencia del tiempo, sino porque el $[\mathrm{sic}]$ presente existencia selecciona del pasado algo

23 Ibid., p. 273.

24 Ibid., pp. 272-273. 
que está vivo todavía, a la vez que rechaza otras cosas que parece haber perdido su potencialidad de la vida. ${ }^{25}$

La humanidad hoy cuenta con criterios y formas de medida axiológicas laicas universalizables por su considerable amplitud incluyente, generalidad y racionalidad expresos en la Declaración Universal de los derechos humanos. Porque el ser humano es historia y en tanto que es su devenir, no olvidan su venir a ser onto y fenoménicamente como hecho de necesidad y de libertad.

Empero, según Karl Marx, la verdadera historia y la conciencia de clase han vivido

Los dos últimos siglos vivieron bajo esa avocación. La historia tenía, [...] un sentido, era realización de un sueño que se presentaba en varias escenas. A menudo expresaba un anhelo de transformación que se resumía en una palabra: revolución. Todo debía empezar de nuevo, desde cero; había que construir un "hombre nuevo" que erigiera la sociedad para siempre emancipada. Nada suscitó más horror ni más esperanza que ese sueño. Por él dieron su vida millones de hombres. [...] "revolución" y "Progreso" fueron las dos palabras que mencionaban un mismo sueño de la razón. Pues bien, ese sueño parece haber terminado. Después de la opresión colonial en nombre de la civilización; luego de dos carnicerías mundiales bajo el lema de la libertad; después de la degradación de la naturaleza por obra de la tecnología, ¿quién puede pronunciar sin un dejo de ironía, la palabra "progreso" [...] Pero la decepción más hiriente ha sido el despertar del sueño revolucionario. La anunciada emancipación del hombre condujo, en la realidad, a una atroz barbarie en los países que la intentaron; la apuesta por la igualdad llevó a la opresión; el anuncio del hombre renovado, a una nueva forma de esclavitud. El sueño se había convertido en pesadilla. ${ }^{26}$

25 Ibid., p. 273.

26 Luis Villoro, De la libertad a la comunidad, México, Tec de Monterrey/Ariel, 2001, pp. 20-21-22. 


\section{MOdERNIDAD: DIGNIDAD HUMANA ÉTICA Y DERECHOS}

En la historia de los dos últimos siglos se dio la instauración de la razón en una sociedad hipotéticamente emancipada, digna del ser humano. Era la afirmación de la libertad, por medio de la cual, según Kant, éste "alcanzaría la mayoría de edad para valerse de su propia razón”. Empero, con el despegue del capitalismo, se da, a la vez, la explotación y la liberación de los seres humanos; la potenciación del individualismo y la libre competencia y del mercado; la mediación de la existencia humana, para convertirla en objeto cosa utilizable y prescindible. Por ello, como apunta Vargas Lozano, el ser humano "tiene que habérselas con eso que llamamos cosas reales".

La modernidad es una forma contradictoria, contraria y opuesta a la recuperación ética y humanitaria del ser humano en la realidad y en el mundo, aunque su obstinación era liberarlo de las inmediateces del mundo de la vida, lo tiene sujetado a las formas de producción y de la reproducción de la realidad histórica. No obstante que "la filosofia se ha propuesto, frente a las profundas desigualdades y contradicciones de la sociedad un ideal de justicia. En otras palabras, la filosofía ha cumplido una función normativa al proponer las características que deberá asumir una mejor organización de la sociedad". ${ }^{27}$ Sin embargo existe el permanente peligro de revertirse con injusticia.

Porque el capitalismo no es un sistema para el bienestar de la humanidad, sino de la competencia y de la ganancia; su verdadero rostro depreda la vida, la naturaleza, el ser humano y la obra humana toda hasta reducirla a sólo mediación de los procesos, donde ya no es el sujeto de la historia: en el mundo donde ya no existen normativas, todo se vale; es decir, ya no existen reglas ni principios éticos, políticos, sociales y económicos regulativos de las

27 Gabriel Vargas Lozano, Filosofía ¿para qué? Desafios de la filosofia en el siglo XXI, México, UAM-Iztapalapa-Ítaca, 2012, p. 34. 
relaciones sociales humanas, expresión clara de la injusticia y la violencia estructural del sistema capitalista neoliberal. Porque "la injusticia se acerca a la justicia escuchando la significación de las experiencias de miseria material o de humillación moral, como si el sufrimiento de esas experiencias (fuera el secreto) en la justicia". ${ }^{28}$

Así, "en el siglo XVII se inicia la configuración de una nueva forma de entender la constitución de la sociedad civil (como) alternativa al absolutismo: el iusnaturalismo. La tesis de que el hombre al nacer ya tiene una serie de derechos y que estos configuran un contrato llamado sociedad civil o política" ${ }^{29}$ será la vía constituyente del iuspositivismo, avanzada histórica y política, que rompe con los universalismos metafísicos incapaces de explicar y entender el mundo de la vida y de la historia ontofenoménica del sujeto social.

Así, puede decirse que los derechos humanos en la actualidad forman parte del campo del derecho, de la filosofía y de la moralidad en una relación dialéctico-conceptual, lo cual ha sido un parteaguas en la historia del derecho, pero sobre todo de la Humanidad: la Declaración Universal de los Derechos Humanos es el marco esencial, el cimiento para la salvaguarda de los derechos universales inherentes al ser humano. Para ello se requiere abordar y desentrañar, desde la iusfilosofía las bases ontoepistémicas de los derechos humanos, del ser humano como sujeto de derecho y de la fundamentación hermenéutica filosófica, ontológica y jurídica, con pretensión de alcance universal a través de los tratados nacionales e internacionales, los cuales deberán ser aplicados y respetados con la intención ontofenoménica de perseverar, en la defensa de la justicia, la equidad solidaria del derecho concebido como universalizable en el mundo. Porque:

El mundo de hoy demanda el reconocimiento y aceptación universal, de los principios y derechos humanos que regulan las relaciones humanas, sociales, económicas, políticas y culturales a través

28 Reyes Mate, Tratado de la injusticia, Barcelona, Anthropos, 2011 , p. 9.

29 Ibid., p. 35. 
de Tratados Internacionales. De otra forma, las sociedades y las organizaciones sociales que han sido perpetradas con tal vileza y perversión, por los individuos que violentan las leyes y los tratados internacionales, [...] perjudican al género humano, y (lo peor) muchas de las veces quedan impunes, por ello es apremiante establecer una jurisdicción universal de Derecho, para que aquellos sujetos que quebranten los Derechos Humanos y la juridicidad, sean juzgados y sancionados, por violentar el bienestar, la salud y la paz mundial. ${ }^{30}$

Así, la abundancia del derecho internacional de los derechos humanos, se ha constituido en la expresión muy especial de la $D e^{-}$ claración Universal de los Derechos Humanos de 1948. Lo cual implica el pacto de los derechos civiles, políticos, económicos, sociales y culturales, "con el propósito de prevenir y de relacionar temas y problemas específicos: la discriminación racial, de la mujer, de los derechos de los niños, de los pueblos indígenas, del genocidio, de la tortura, de la protección del medio ambiente, etc." ${ }^{31}$

Es importante hacer notar que

El Derecho Internacional de los Derechos humanos es: el cuerpo de reglas internacionales, procedimientos e instituciones elaboradas para implementar las ideas de que toda nación tiene la obligación de responder a los derechos humanos de sus ciudadanos y que las otras naciones y la comunidad internacional tiene la obligación y el derecho de vigilar el cumplimiento de esa obligación. ${ }^{32}$

Es necesario señalar que la pretensión de universalidad está vinculada con los derechos humanos, con su fundamento ontológico y ético en la fenomenicidad transida de particularismos. Pero aquí

30 Mario Magallón Argüelles, El Estatuto de la Corte Penal Internacional y su Incompatibilidad con la Constitución Política Mexicana, México, 2013, p. 7, tesis, Facultad de Derecho de la Barra Nacional de Abogados.

31 Ibid., p. 2.

32 Alejandra Montoya Mexia, El Estatuto de la Corte Penal Internacional y su incompatibilidad con la Constitución Mexicana, México, Ángel editor, 2007, p. 29. [N. A. Las cursivas son de la autora]. 
nos encontramos con el problema de cuestiones de método, donde las formas inductivas tienen la pretensión de alcanzar principios auténticamente universalizables lógico-formales.

Esto es una amplia discusión intercultural apenas iniciada en los diversos campos teóricos y epistemológicos, lo que hace posible construir conceptos y categorías de certeza y facticidad en la dialecticidad procesual, en la construcción dialógica de formas discursivas, todo lo cual merece ser llamado como lo universal ético y práxico de la ética y de los derechos humanos. Lo cual implica una reflexión antropológica humanista que requiere reconstruir la vida humana en la realidad de una época como un ejercicio paidético. Es decir, que

Por limitados, controversiales y perfectibles que sean los derechos humanos, sobre todo desde las perspectivas del multiculturalismo, ellos son los principales e irreversibles parámetros éticos, ético políticos y ético jurídicos de carácter laico, humanista y racionalidad que ha aportado la modernidad a la historia universal. Constituyen, en efecto, la "tabla de valores" de nuestro tiempo. La autoconciencia crítica de sus límites forma parte de lo que ellos mismos posibilitan e incluso propician. ${ }^{33}$

Desde la perspectiva filosófica, ética y de derecho es posible relacionar los derechos sociales, políticos, económicos, jurídicos y sus vínculos con las diversas áreas del derecho, de la dignidad humana, de los campos del conocimiento de la obra humana y de las relaciones de convivencia social; allí donde la dignidad de los seres humanos puede ser vulnerada y requerir de protección y tutela del Estado y de las instituciones nacionales e internacionales de derechos.

En este sentido, la infracción o violación de los derechos humanos es no sólo un quebranto legal sino también ético de los valores humanos y, de manera más radical, compromete la propia condición humana. Y ésta se cifra, en definitiva, en la naturaleza libre y co-

33 Juliana González Valenzuela, Genoma humano y dignidad humana, España FFyL/UNAM/Anthropos, 2005, p. 62. 
munitaria del hombre, en su constitutiva igualdad, su racionalidad, su individualidad y su diversidad. Se trata, es verdad, de valores, ideales y virtudes que gravitan todos en torno a la idea central de dignidad humana. ${ }^{34}$

Ante esta realidad, reconstruir la vida humana permite observar la debilidad ético conceptual y de derechos como base del pensamiento racional. El desarrollo intelectual en derechos y obligaciones requiere de una fundamentación filosófica y ética de una paidética que implica una filosofía y una humanización del ser humano. ${ }^{35}$ Porque toda filosofía es filosofía de la educación. La filosofía de la educación tiene la impostergable tarea de reflexionar sobre el importante papel de educar, porque educar es gobernar. Allí donde la pedagogía de la realidad implica la autoposición y gobierno ético de la vida humana en la unidad ontológica del ser humano y de la diversidad óntico-fenoménica de la alteridad como ente situado históricamente.

Es decir, se trata de un cuerpo de doctrina que permite transitar por los diversos campos de las humanidades, las ciencias sociales y naturales.

Es una filosofía de la alteridad que aplica los valores de equidad, justicia, autonomía y libertad en relación de interdependencia y de las interinfluencias entre las diversas formas de concebir la filosofía en general y las filosofías prácticas en particular. Es la reflexión dialógica de intercambios e interrelaciones, entre formas culturales y filosóficas y por extensión entre las políticas de la filosofía (en el mundo globalizado). ${ }^{36}$

En la nueva concepción de dignidad humana están implícitos: posición, decoro, prestigio, dignidad, aprecio, precisión, reconoci-

34 Ibid, p. 63.

35 Cfr., Samuel López Olvera, Una propuesta paidética desde la filosofia de Xavier Zubiri, Toluca, 2014. Tesis, Instituto de Ciencias de la Educación del Estado de México.

36 Mario Magallón Anaya, Filosofía y politica mexicana en la Independencia y la revolución, México, Quiviria, 2013, p. 121. 
miento, mérito, alto rango existencial. Lo que parece tener significado en diversos órdenes: axiológicos, ontológicos, éticos, jurídicos, políticos y sociales. Allí donde la dignidad está cifrada por la libertad; donde dignidad, libertad y humanidad están co-implicados dialéctica e históricamente. En este sentido, puede decirse que los derechos humanos en el mundo actual tienden a superar la fragmentación de la condición humana y de la vida. Así,

Los derechos humanos expresarían la superación de toda fragmentación y de la condición humana; el impulso de la moralidad, como emergencia y como resistencia, no podría ser entendido al margen de aquellos derechos, y el lenguaje de ese mundo que pretendemos que sea nuestro mundo no alcanzará una real fuerza discursiva si no asumimos la utopía. La exigencia de los mundos posibles surge de una injuria radicalmente profunda, oculta en los pliegues mismos de los códigos de las legislaciones de los pueblos. Nadie nos puede negar el derecho de soñar en un cielo puro de derecho, que nada tiene que ver con un Kelsen. Es, por todo lo que venimos diciendo, un saber y una praxis de denuncia de las variadas formas de perversión teórica con la que se distorsiona la relación mundo-lenguaje, tal como se la ejerce en el acto mismo de la negación de los derechos humanos, como sucede en aquellos para los que, desde la aristocracia del ser, el resto de los humanos constituye el mundo de lo banal. Digamos que la banalidad, más no por ello se pierde la índole humana, también podemos perderla desde las honduras del filosofar. ${ }^{37}$

La dignidad humana define al ser humano tanto en su ser como en su valer. Es decir, el ser humano vale por lo que es en sí mismo y por lo que vale cualitativamente como humanitas, como aquello que le da especificidad diferenciadora, como un centro móvil capaz de ascender y descender fenoménicamente en lo ético y lo ontológico. Allí donde el ser humano es un fin en sí mismo, nunca es medio u objeto de manipulación. El tiempo de hoy ha dado grandes

37 Arturo Andrés Roig, "Condición humana, derechos humanos y utopía", en Horacio Cerutti Guldberg y Rodrigo Páez Montalbán, América Latina: democracia, pensamiento y acción, México, CGyDEL/UNAM/Plaza y Valdés, 2002, p. 112. 
pasos éticos, políticos, sociales, económicos y culturales de ilimitada trascendencia histórica al buscar superar las estructuras atávicas de dominio y cosificación del ser humano por otro ser humano; en la actualidad se transita hacia el reconocimiento de la dignidad humana orientado por los derechos y los valores humanos.

Sin embargo, en el sistema mundial se han globalizado las desigualdades, la pobreza, las exclusiones, la miseria, la desesperanza, la explotación, el subdesarrollo económico, científico y tecnológico, pero, de forma muy particular, la violencia en sus muy variadas y diversas expresiones: materiales, simbólicas, icónicas, psicológicas, lingüísticas y de escritura, así como la más diversa gama de expresiones sociales, políticas, sociológicas, culturales, etcétera, lo cual se expresa a través de los problemas de género, corrupción, narcotráfico, inequidad, desigualdad, injusticia y falta de una práctica ética y comprometida y responsable con el otro en las relaciones de alteridad, entre nosotros y los otros, como del género humano.

Donde la violencia es el espacio en que se da el fin de la razón y de la racionalidad para imponer las prácticas del poder unidimensional a nivel mundial desde un proyecto neoliberal global regido por la macroeconomía y la economía política de relaciones desiguales no democráticas. Walter Benjamin había señalado que se ha roto la armonía entre el ser humano y la naturaleza, las sociedades y el mundo; los imaginarios equilibrios de la modernidad no existen o, según nuestro entender, nunca existieron, donde el progreso automático, infinito y constante, nunca existió, donde la historia tampoco es progresiva y unidireccional.

Según Benjamin esta ruptura trágica entre el ser humano y la naturaleza puede apreciarse de forma fantástica en la pintura de Paul Klee titulada el Ángelus Novus, caracterizada por los "ojos desorbitados", "boca abierta", "alas tendidas", esta no es otra que la caracterización del "Ángel de la historia". Es decir, ese que se muestra y se hace presente, con "su rostro que está vuelto hacia el pasado. En lo que para nosotros aparece como una cadena de acon- 
tecimientos, él ve una catástrofe única, que arroja a sus pies ruina sobre ruina $[\ldots]$ ". Pero el ángel de la historia busca "detenerse, despertar a los muertos y recomponer lo destruido." Empero, un fuerte "huracán [...] lo arrastra irresistiblemente hacia el futuro. Al cual vuelve las espaldas. [...] Este huracán es lo que nosotros llamamos progreso". ${ }^{38}$

La historia y el progreso está permanentemente jalonado por los modos de producción y las fuerzas productivas, donde el tiempo históricamente no es uniforme, sino desigual, ese ha sido el modo del acontecer histórico, hasta arribar a la historicidad global de los grandes acontecimientos de destrucción y muerte del siglo XX, de explotación, miseria, destrucción, desigualdad, injusticia, etc.

Todo ello es consecuencia del reparto inequitativo y desigual de la riqueza, de la justicia social y de los derechos humanos. Es la experiencia de la crisis, de la práctica axiológica en el caos mundial. La aceleración y la expansión de las finanzas a lo largo y a lo ancho del planeta ha frenado, e incluso derruido, la imaginación creativa de millones de personas que creyeron ver en el portentoso poder económico norteamericano el nacimiento de una nueva era en las bolsas de valores, una nueva fuente de bienestar compartido y, hasta hipotéticamente, en cierta medida democrático.

Por otro lado, las empresas transnacionales globales aceleraron su marcha mundial y propiciaron la apertura de los fabulosos mercados de Oriente, a las vez que acentuaron el perfil productivo mundializado; estos principios liberales de soberanía y de autodeterminación de los Estados-nacionales, considerados, en otros tiempos, el eje articulador de la política y de la economía internacional, habían sido cuestionados décadas antes por sociólogos, politólogos, economistas, entre muchos otros pensadores.

38 Cfr., Walter Benjamin, Tesis sobre la historia y otros fragmentos, México, Ítaca/ UACM, 2008, pp. 44-45. 
En la cultura, en la difusión y la apropiación de principios, de valores y de ideas es donde se da con mayor profundidad el proceso de globalización, no sólo como tendencia real dominante, sino, particularmente, como narrativa del fenómeno capaz de estimular la imaginación colectiva y concitar las más variadas y encontradas reacciones nacionalistas, defensivas unas, cosmopolitas, agresivas, o entusiastas otras, ante el nuevo mundo que se va haciendo presente. Empero, todas estas reacciones tienen el registro de la impronta de raíz global, tanto en sus orígenes como en sus implicaciones, independiente de sus significados contradictorios y autonómicos. Así:

La globalización de los medios tiende a la reducción de la densidad intelectual de la información, a su transferencia de noticias de razones a noticias de sensaciones, donde las audiencias y las circulaciones masivas sean más importantes en términos de clientes potenciales para los productos que anuncian que para que se vayan formando una opinión, a través del conocimiento, que les permita debatir los temas que les son relevantes y tomar las decisiones que les sean significativas. ${ }^{39}$

En la realidad global neoliberal la concepción de justicia con equidad ha sido estudiada por filósofos y teóricos políticos; en el análisis de los derechos humanos la justicia, la equidad, la solidaridad y la autonomía está implícito el principio de tolerancia, el cual debe ser entendido como el respeto por la diversidad, la diferencia, la pluralidad de ideas o formas de pensar, de creencias religiosas, políticas, culturales, sexuales y de género, del reconocimiento de las minorías étnicas, políticas, sociales y culturales.

Por ello, la tolerancia del liberalismo ilustrado de la modernidad es ya insuficiente, porque ya no puede ser: "dejar hacer y dejar pasar". Por ejemplo, "te tolero, porque no me queda de otra"; "tolero que te mueras de hambre y que te humillen", este tipo de tolerancia

39 Raymundo Riva Palacio, "El desafío silenciosos", en León García Soler (coord.), La palabra y los derechos humanos, México, Comisión Nacional de los Derechos Humanos, 2004, p. 79. 
es cómplice de las peores formas de relación humana y social, es un atentado en contra de los derechos humanos y sociales. La tolerancia y sus prácticas requieren resignificarse y resemantizarse de acuerdo con los tiempos, desde una praxología solidaria con equidad y justicia. 